\title{
Study on influence of upstream pier on scour depth of downstream pier
}

\author{
Ying Qiang ${ }^{1, a}$, Jia Dongdong ${ }^{1, b}$, Zhang Xingnong ${ }^{1, c}$ and Chen Zhangying ${ }^{1, d}$ \\ ${ }^{1}$ Key Laboratory of Port, Waterway and Sedimentation Engineering of Ministry of Transport \\ of the People's Republic of China, Nanjing Hydraulic Research Institute, Nanjing China \\ agying@nhri.cn, ${ }^{b}$ ddjia@nhri.cn, ${ }^{c}$ xnzhang@nhri.cn, ${ }^{d}$ cychen@nhri.cn
}

Keywords: Bridge Group; pier; flow pattern; scour.

Abstract: Flow field downstream of the pier were divided two parts, the main channel area, and the pier area. On the basis of the main flow stress, the formula of main flow velocity variation along the distance was deduced. Combined with the formula of bridge pier scour depth in the handbook, the downstream local scour depth, affected by an upstream pier, can be calculated. As a case in point, the calculated scour depth of the Wulongjiang bridge pier was compared with the experimental value and found similar.

\section{Introduction}

With the development of the economy, the phenomenon that two or more bridges constructed close to each other will occur frequently. When the bridge construction at upstream affects the downstream bridge's flow pattern, riverbed erosion, and navigation conditions, we can consider these bridges as a bridge group.

At present, the bridge group researches mainly focus on the navigation aspect to form as "tunnel" effect by the bridge group [1 3]. There is little research on the scour depth and morphology of group bridges. This paper utilizes the bridges group in Wulongjiang river, Fujian province to study the flow pattern change and effect of pier scour pit.

\section{Selection of bridge group and erosion test results}

The 5 bridges in Fuzhou city on the Wulongjiang River, south branch of the Minjiang River forms a bridge group and are selected as the research object as in Figure 1. There are the Wulongjiang bridge built in 1971; the Fuzhou Xiamen railway bridge built in 2008, which is located in the upstream of the Wulongjiang bridge 220m; double track bridge of Wulongjiang was built in 2012, which is located in the downstream of the Wulongjiang bridge 50m; Fuzhou Pingtan railway bridge and Fuzhou Xiamen high-speed railway bridge are in construction located upstream $180 \mathrm{~m}$ and $70 \mathrm{~m}$ of the highway bridge respectively. These bridge piers are placed in counterpart condition affecting each other. In order to study the effect of bridge construction on the base of flow and bed topography, A normal trapezoid flume model of vertical scale and vertical scale is designed and the sawdust as model sediment chosen. Two schemes are tested: Scheme 1 is $30 \mathrm{~m}$ of water depth and $2.50 \mathrm{~m} / \mathrm{s}$ of velocity; Scheme 2 is $25 \mathrm{~m}$ of water depth and $1.50 \mathrm{~m} / \mathrm{s}$ of velocity. The test washout times lapse for 5 hours.

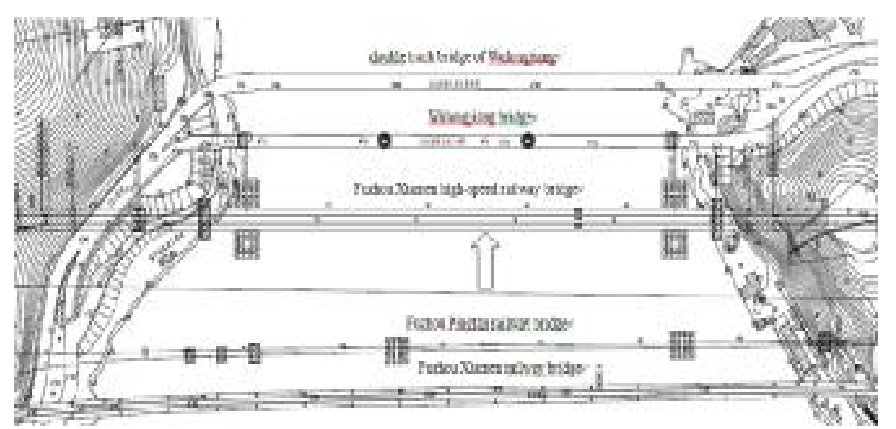

Fig. 1 Wulongjiang Bridge, built and proposed bridges nearby

Single bridge pier scour features: the end 
of test scheme 1, the general scour depth of riverbed is $3.2 \mathrm{~m}$, the maximum depth of local scour is $13 \mathrm{~m}$ at the bridge section, shown in Figure 2; at end of scheme 2, the general scour depth of riverbed is about $1.1 \mathrm{~m}$, the maximum depth of local scour is $6.9 \mathrm{~m}$.

The double bridge piers scour characteristics: after the construction of Fuzhou Xiamen railway bridge, water flows through the pier of the Fuzhou Xiamen railway bridge and forms Carmen vortex in the downstream. Silt settles as sediment inner the vortexes area as the velocity is low. Sand ridge is predicted in the model, as in figure 3. The general scour depth of Wulongjiang bridge is $3.8 \mathrm{~m}$ at section for scheme $1,0.6 \mathrm{~m}$ deeper than the single bridge. The maximum depth of local scour is $11 \mathrm{~m}$, $2 \mathrm{~m}$ less than that of the single bridge, as seen in Figure 3. In scheme 2, The general scour depth is $1.25 \mathrm{~m}, 0.15 \mathrm{~m}$ deeper than a single small bridge with the same the velocity while the maximum depth of local scour is $6.2 \mathrm{~m}, 0.7 \mathrm{~m}$ less than that of the single bridge.

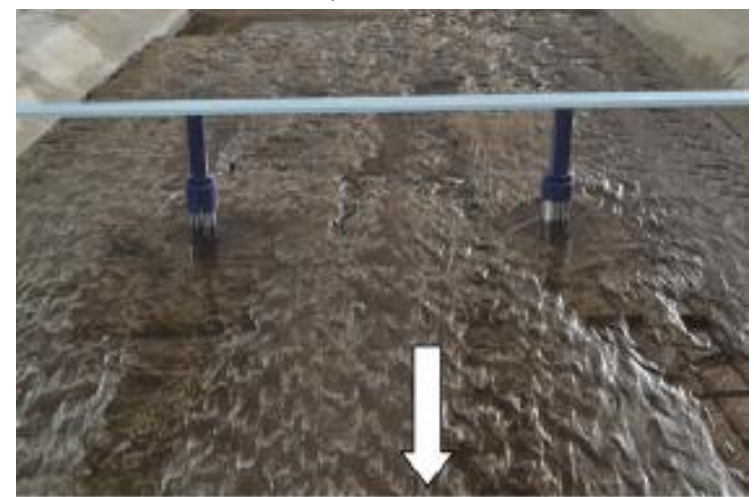

Fig. 2 Scour topography near the pier with single bridge

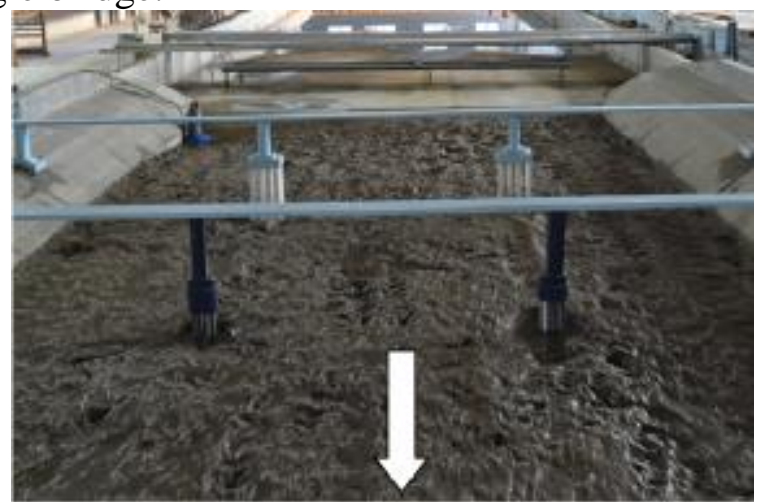

Fig. 3 Scour topography near the pier with double bridges

\section{Calculation of scour depth of pier when group bridges}

Based on incoming flow conditions, choose the appropriate formula to calculate the scour depth of pier for a single bridge. This formula can depict the velocity profile at downstream of the pier. Then, the velocity at specific position can be reapplied $t$ formula can be determined the velocity of a position downstream of the bridge pier where may be construct another bridge. Then we can use the scour depth formula to calculate the scour depth of the downstream bridge and thus determine that of the third bridge.

Selection of local scour depth formula: He, Xiaolan[4] compared the calculation formulas of the local scour depth of piers in China, the former Soviet Union, and the United States. The calculated value of local scour of piers in Chinese and the former Soviet's formula is larger than the American's. The calculated values obtained by Chinese formula are more consistent with the simulated and measured values than the other two. Therefore, the calculation of local scour depth is carried out by using the formula in "hydrological specifications for survey and design of highway engineering" [5]: the scour depth of piers in the model is affected by the interaction of pier, pile cap and pile column. The method of calculating local scour of pier include pile cap and pile column is given in hydrological specifications appendix B, i.e.

$$
h_{s}=\left(k_{\xi}{ }^{\prime} k_{m \phi} k_{h \phi} \phi^{0.6}+0.85 k_{\xi 1} k_{h 2} B_{1}^{0.6}\right) * k_{\eta 1}\left(v_{0}-v_{0}{ }^{\prime}\right)\left(\frac{v-v_{0}{ }^{\prime}}{v_{0}-v_{0}{ }^{\prime}}\right)^{n_{1}}
$$

In which: $k_{\xi}{ }^{\prime}=0.95$, shape coefficient of single pile column ; $k_{m \phi}$ coefficient of pile column group; $k_{h \phi}$ reduction coefficient of submerged pile column; $\phi$ diameter of pile column; $k_{\xi 1}$ coefficient of pier shape; $B_{1}$ calculate width for Pier; $k_{h 2}$ reduce coefficient of cap; $k_{\eta 1}=0.8\left(\frac{1}{\bar{d}^{0.45}}+\frac{1}{\bar{d}^{0.15}}\right)$ influence coefficient for sediment particle bed; $\bar{d}$ average particle diameter, mm; 
$v_{0}=0.0246\left(\frac{h_{p}}{\bar{d}}\right)^{0.14} \sqrt{332 d+\frac{10+h_{p}}{\bar{d}^{0.72}}}$ incipient velocity of sediment $(\mathrm{m} / \mathrm{s}) ; \quad v_{0}{ }^{\prime}=0.462\left(\frac{\bar{d}}{B_{1}}\right)^{0.06} v_{0}$ initial scour velocity for the sediment in front of pier $(\mathrm{m} / \mathrm{s}) ; n_{1}$ as index, $n_{1}=\left(\frac{v_{0}}{v}\right)^{0.25 \bar{d}^{0.19}}$.

Based on the actual sizes of pier, pile column and pile cap of Wulongjiang bridge [6], and flow conditions of test, the formula (1) is used to calculate the scour depth of the No.2 bridge pier. The calculation results are shown in table 1 . As the table shows, the calculated local scour depth is $12.73 \mathrm{~m}$ for scheme 1. This value is obtained with general scour $3.2 \mathrm{~m}$, close to the experimental results of 13 $\mathrm{m}$. The calculated local scour depth is $9.53 \mathrm{~m}$ for scheme 2 . This value is obtained with general scour $1.1 \mathrm{~m}$, larger than the experimental results of $6.9 \mathrm{~m}$.

Tab.1 The local scour depth calculated by the hydrological specifications formula

\begin{tabular}{|c|c|c|c|c|c|c|c|c|}
\hline $\begin{array}{c}\text { sche } \\
\mathrm{me}\end{array}$ & $\begin{array}{c}\mathrm{U} \\
(\mathrm{m} / \mathrm{s})\end{array}$ & $\begin{array}{c}\mathrm{H}_{\mathrm{P}} \\
(/ \mathrm{m})\end{array}$ & $\begin{array}{c}\mathrm{d} \\
(\mathrm{mm})\end{array}$ & $\begin{array}{c}\mathrm{V}_{0} \\
(\mathrm{~m} / \mathrm{s})\end{array}$ & $\begin{array}{c}\mathrm{V}_{0} \\
(\mathrm{~m} / \mathrm{s})\end{array}$ & $\mathrm{n}$ & $\begin{array}{c}\mathrm{Hs} \\
(\mathrm{m})\end{array}$ & $\begin{array}{c}\text { Test } \\
\mathrm{Hs} \\
(\mathrm{m})\end{array}$ \\
\hline 1 & 2.26 & 33.2 & 0.54 & 0.69 & 0.27 & 0.77 & 12.73 & 13 \\
\hline 2 & 1.44 & 26.1 & 0.54 & 0.65 & 0.25 & 0.84 & 9.53 & 6.9 \\
\hline
\end{tabular}

Downstream flow structure of single bridge pier: The velocity distribution of downstream pier is similar to that of downstream spur dike [7]. By means of the research results of downstream velocity distribution of spur dikes, the flow of downstream pier is divided into two parts: the main region and pier region (Figure 4). Velocity in the pier region is smaller; velocity in the main region is larger. These two streams flow in parallel with each other at different velocities, mixing and interacting with each other at the intersection, resulting in mass and momentum exchange between the two parts of water.

With the main region as the research object, a water body ABCD- $A^{\prime} B^{\prime} C^{\prime} D^{\prime}$ as in figure 5 is taken. According to the principle of momentum balance, the change rate of water flow momentum is

$$
\mathrm{d} K=\mathrm{d} P+\mathrm{d} G+\mathrm{d} T_{\mathrm{b}}+\mathrm{d} T_{\mathrm{w}}+\mathrm{d} T_{\mathrm{r}}
$$

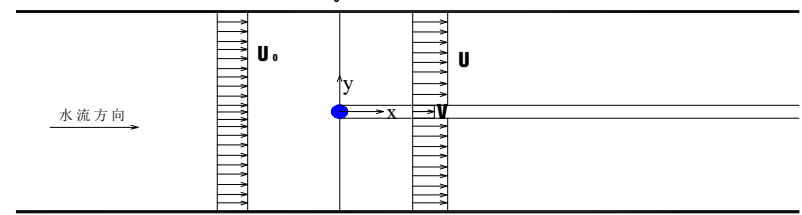

Fig. 4 The velocity distribution of downstream pier

In the formula: $\mathrm{d} P=P_{A B C D}-P_{A^{\prime} B^{\prime} C^{\prime} D^{\prime}} \approx-\gamma h(B-\mathrm{b}) \mathrm{d} h$ is component of water pressure in the $\mathrm{x}$ direction; $\quad \mathrm{d} G=\gamma\left(h+\frac{\mathrm{d} h}{2}\right)(B-b) \mathrm{d} x J_{\mathrm{b}} \approx \gamma h(B-b) J_{\mathrm{b}} \mathrm{d} x \quad$ is component of water gravity in the $\mathrm{x}$ direction; $J_{\mathrm{b}}$ is gradient of riverbed; $\mathrm{d} T_{\mathrm{b}}=-\tau_{\mathrm{b}}(B-b) \mathrm{d} x$ is bed resistance; in general, the value of $\mathrm{h} / \mathrm{B}$ is small, side wall resistance $\mathrm{d} T_{\mathrm{w}}$ can be negligible; $\mathrm{d} T_{\mathrm{r}}=-\tau_{\mathrm{r}} H \mathrm{~d} x$ is shear resistance on the interface between the main region and pier region.

After analyzing the surface of longitudinal slope, turbulent shear stress on the interface of two body and the shear stress, the (3) of main region velocity variation along $\mathrm{x}$ is obtained:

$$
\left(\frac{U-U_{0}}{U_{\mathrm{e}}-U_{0}}\right)^{\frac{B-2 b}{2 B}}\left(\frac{U_{1}-U_{\mathrm{e}}}{U_{1}-U}\right)=\exp \left[0.66\left(1-\frac{x}{e x_{1}}-\mathrm{e}^{-\frac{x}{x_{1}}}\right)\right]
$$

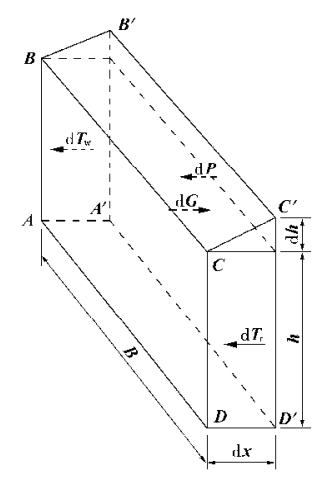

Fig. 5 Stress analysis of the main flow 
Where: $\mathrm{U}$ is average velocity of cross section at $\mathrm{x}$ in main region; $U_{0}=\frac{Q}{B \mathrm{H}}$ is average velocity of cross section, $Q$ is discharge, $B$ is the flume width, $H$ is depth; $U_{1}=\frac{B}{B-2 b} U_{0}$ b is diameter of pier; $U_{e}=\frac{B}{B-b} U_{0}$ is average velocity of cross section at pier $(\mathrm{x}=0)$ in main region; $x_{1}$ is the distance for the pier section to the contracted section.

Discussion and verification of downstream flow field of single bridge pier: The formula (3) shows that in the bridge section $x=0$, the velocity of main $U=U_{e}$; in the contracted section $x=x_{1}$, maximum velocity of main region; in the distance $x=\infty$, the velocity of main region is equal to the mean velocity in section $U=U_{0}$.

Liu, Jialun [3] carried out the calculation of the flow velocity after the pier acted on the simulated flume, the length and width of flume were $5000 \mathrm{~m}$ and $800 \mathrm{~m}$, the average velocity is $3 \mathrm{~m} / \mathrm{s}$. There were arranged 4 Piers and 5 apertures in flume, each pier diameter is $25 \mathrm{~m}$, the clean width of 5 apertures is $50+100+400+100+50 \mathrm{~m}$, the velocity distribution of centerline in main navigation $(400 \mathrm{~m})$ is obtain by calculated, there are shown in Figure 6.

It is assumed that the discharge through the main navigable aperture is $\mathrm{Q}_{400}=400 \times 3 \times \mathrm{H}$, and the $x_{1}=3 \mathrm{~b}$ is taken, the average velocity of the main navigable aperture with $\mathrm{x}$ changes is calculated by formula (3). The curve is shown in figure 6 . The formula can reflect the

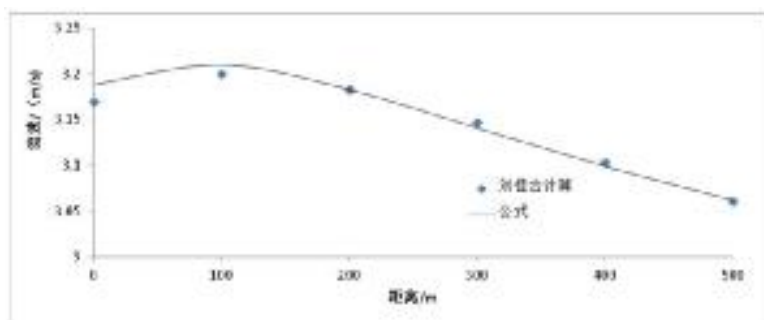

Fig. 6 Velocity distribution along the main navigation axis variation of flow velocity in the main region, and the values are basically consistent with the reference [3].

Calculation of pier scour under the action of Bridge Group: Calculation of the flow velocity at the bridge pier of the downstream Bridge: Fuzhou Xiamen railway bridge is on the most upstream of the bridge group. 220m downstream of Fuzhou Xiamen bridge is Wulongjiang Bridge. Per the data of Fuzhou Xiamen Railway, the Pier has pier, pile cap and pile column in the water. This type of structure has a complicated effect on water flow. For the convenience of calculation, the obstruct width is obtained through the sum of obstruct area of each parts and then divided by the depth. It is concluded that the average obstruct width of piers at $30 \mathrm{~m}$ depth is $11.59 \mathrm{~m}$ and at $25 \mathrm{~m}$ depth is $11.11 \mathrm{~m}$, then use the formula (3) to calculate the velocity of Wulongjiang bridge after the completion of Fuzhou Xiamen Railway bridge, velocity values of two schemes are shown in table 2.

Tab.2 The velocity of Wulongjiang Bridge section after Fu-Xia Railway Bridge construction

\begin{tabular}{|c|c|c|c|c|c|c|}
\hline scheme & $\begin{array}{l}\text { Distanc } \\
\mathrm{e} \\
\mathrm{x} \\
/ \mathrm{m}\end{array}$ & $\begin{array}{c}\text { Aperture } \\
\text { width } \\
\text { B } \\
\text { /m }\end{array}$ & $\begin{array}{c}\text { Pier } \\
\text { width } \\
\text { b } \\
/ \mathrm{m}\end{array}$ & $\begin{array}{c}\text { Mean } \\
\text { velocity } \\
\mathrm{U}_{0} \\
/(\mathrm{m} / \mathrm{s})\end{array}$ & $\begin{array}{c}\text { Main } \\
\text { region } \\
\text { velocity } U \\
/(\mathrm{m} / \mathrm{s})\end{array}$ & $\begin{array}{c}\text { Pier region } \\
\text { velocity V } \\
/(\mathrm{m} / \mathrm{s})\end{array}$ \\
\hline 1 & 220 & 144 & 11.59 & 2.55 & 2.63 & 1.66 \\
\hline 2 & 220 & 144 & 11.11 & 1.64 & 1.68 & 1.12 \\
\hline
\end{tabular}

Calculation of scour depth at the bridge pier of the downstream Bridge: Table 2 calculation shows that after the complete of Fuzhou Xiamen railway, the velocity of Wulongjiang bridge under the two schemes were 1.66 and $1.12 \mathrm{~m} / \mathrm{s}$. The local scour depth of pier is calculated by formula (1). The calculated results are shown in table 3. Comparing the results of calculation and experiment, the maximum depth of local scour of scheme 1 is $9.94 \mathrm{~m}$ and $11 \mathrm{~m}$, the calculated value is slightly smaller than the test one; the scour depth of scheme 2 is $7.60 \mathrm{~m}, 6.2 \mathrm{~m}$ respectively, the calculated value is slightly larger than the test one. 
Tab.3 Scour depth of Wulongjiang Bridge after Fu-Xia Railway Bridge construction

\begin{tabular}{|c|c|c|c|c|c|c|}
\hline $\begin{array}{l}\text { Pier } \\
\text { region } \\
\text { velocity } \\
\text { U } \\
(\mathrm{m} / \mathrm{s}))\end{array}$ & $\begin{array}{c}\text { Water } \\
\text { depth } \\
\mathrm{H}_{\mathrm{P}} \\
(\mathrm{m})\end{array}$ & $\begin{array}{l}\text { Sediment } \\
\text { diameter d } \\
(\mathrm{mm})\end{array}$ & $\begin{array}{c}\text { incipient } \\
\text { velocity } \\
\text { Vc } \\
(\mathrm{m} / \mathrm{s})\end{array}$ & $\begin{array}{c}\text { initial } \\
\text { scour } \\
\text { velocity } \\
\text { V' } \\
(\mathrm{m} / \mathrm{s})\end{array}$ & $\mathrm{n}$ & $\begin{array}{c}\text { Scour } \\
\text { depth } \\
\text { Hs } \\
(\mathrm{m})\end{array}$ \\
\hline 1.66 & 30 & 0.54 & 0.67 & 0.26 & 0.82 & 9.94 \\
\hline 1.12 & 25 & 0.54 & 0.64 & 0.25 & 0.89 & 7.60 \\
\hline
\end{tabular}

\section{Conclusion}

(1) The formula in hydrological specifications, this time formula(1), gets selected based on the flow conditions, diameter of sediment and the type of Wulongjiang bridge pier in the model test, to calculate the scour depth effected by pier, pile cap, pile column. The scour depth of piers is calculated by formula (1) and the calculation results are compared with the experiment value. The difference is small. The formula (1) can be used to calculate the scour depth acted by different velocity.

(2) The flow of downstream pier is divided into the main region part and pier region part. Flow momentum equation of the main region is listed: the formula (3) of main region velocity variation with $\mathrm{x}$ is obtained. The formula is validated by the results of others. That formula reflects the variation of flow velocity in the main region and these values are consistent with other people's results. The formula can reflect the variation of flow velocity in the main region and is consistent with the reference.

(3) The velocity and the scour depth of Wulongjiang bridge after the completion of Fuzhou Xiamen Railway bridge are calculated by used the formula (3) and formula (1). Its results basically reflect the change of scour depth.

\section{Acknowledgements}

This work was financially supported by the Nanjing Hydraulic research institute (Y210015)

\section{Reference}

[1] Peng J. X. On Navigational Standard of Bridge Group Crossing River. Port \& Waterway Engineering. (2008). P. 73.

[2] Qiu Y. Shen Xiaoxiong. Analysis of the laneway effect of pipeline bridge. Journal of transport science and engineering, (2011). P. 46.

[3] Liu J. L. Research on the Navigation Impacts of Bridge Group Channel Based on 2-D Flow Field Simulations. Wuhan University of Technology. 2013.

[4] He X. L, Li Q. Preliminary analysis of local scour of pier across River Bridge. China Water Transport. Vol. 13, (2013). P. 198.

[5] JTG C30-2002. hydrological specifications for survey and design of highway engineering. highway. (2002).

[6] The writing group of wulongjiang Bridge, Fujian province. Design and construction of wulongjiang bridge. People's traffic press. Beijing: (1982).

[7] Ying Q, Jiao Z. B, Kong X. B. Hydraulics of spur dikes. Ocean Press. (2004). 